\title{
Holistic Dentistry in Evolving Evidence Based Dental Curriculum
}

\author{
S Jeelani* \\ Reader, Department of oral medicine and radiology, Sri venkateshwaraa dental college, puducherry, India
}

*Corresponding author: S Jeelani, Reader, Department of oral medicine and radiology, Sri venkateshwaraa dental college, puducherry, India

\section{ARTICLE INFO}

Received: 㹃 July 03, 2020

Published: 㗀 July 13, 2020

Citation: S Jeelani. Holistic Dentistry in Evolving Evidence Based Dental Curriculum. Biomed J Sci \& Tech Res 28(5)-2020. BJSTR. MS.ID.004709.

\section{ABSTRACT}

General examination is regarded as a systematic simple diagnostic tool. General appraisal of the patient goes a long way in treating the patient as a whole which is termed as holistic care. A dozen of relevant facts are significant in relation to this context which includes Gait, Built, Posture, Skin, Hair, Skull, Hand and finger nails, Facial form, Jaws, Eyes, Ears, Nose.

Keywords: Diagnosis; General Examination; Medicine; Oral Medicine

\section{Short Communication}

Every great work has a simple beginning. The same concept applies to diagnosis in the field of Medicine as well. In this context a diagnosis applies not just to the patient complaint but looking at the patient as a whole and not just the problem. This is where general examination is regarded as a systematic simple diagnostic tool. Though advances in science are endless but going into the depths every complex investigation needs a simple start and this simple start begins from the moment a patient enters a doctor's workplace - a general appraisal of the patient goes a long way in treating the patient and not just the problem. Just like although life is a boon however a healthy life is a blessed boon so is the information contributed by general examination an added super specialty practiced by a simple dentist and in particular a specialist in Oral Medicine serving as a life saving link to various specialties in the field of Medicine.

\section{Steps In General Examination}

A simple approach is to look at the patient wholesome which gives an extra edge in holistic approach. A dozen of relevant facts are significant in relation to this context which includes

a. Gait
b. Built
c. Posture
d. Skin
e. Hair
f. Skull
g. Hand and finger nails
h. Facial form
i. Jaws
j. $\quad$ Eyes
k. $\quad$ Ears
l. Nose

\section{Gait}

Gait refers to manner in which one walks and this can contribute a great deal of information. Gait abnormalities can be from local, neurological and muscular causes. The different types of gait include (Figure 1). 


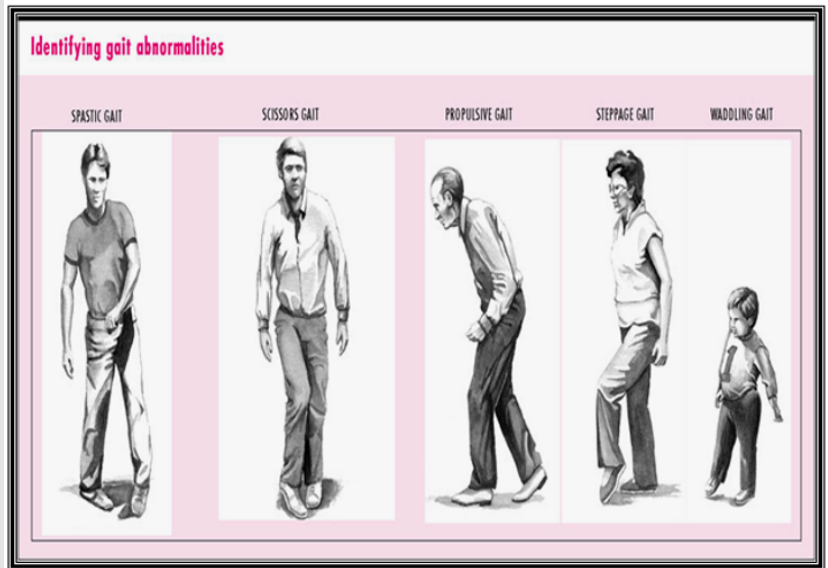

Figure 1.

\section{Built}

Built refers to the body proportion and normally referred to as esthenic ie, well proportionate built in consistent with an individual's chronological age. The extremes of abnormal built include (Figure 2).

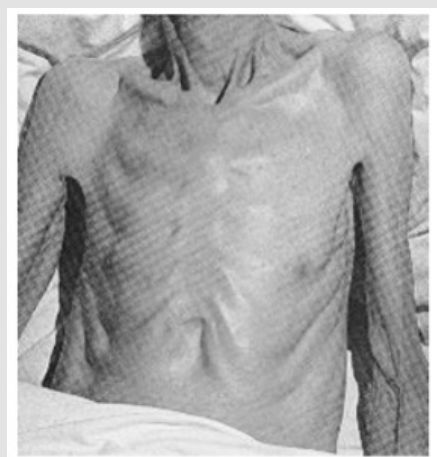

a

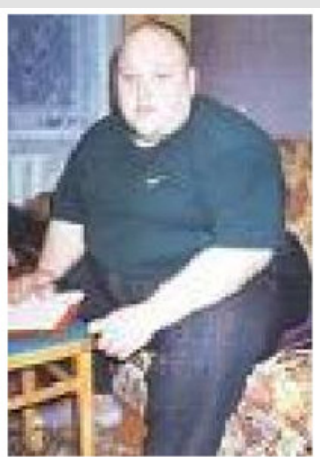

b

Figure 2: a) Aesthenic; b) Hypersthenic.

\section{Posture}

Posture refers to position of an individual may it be sitting or standing. Abnormal postures (Ergonomics) can result in Musculoskeletal problems (Figure 3).
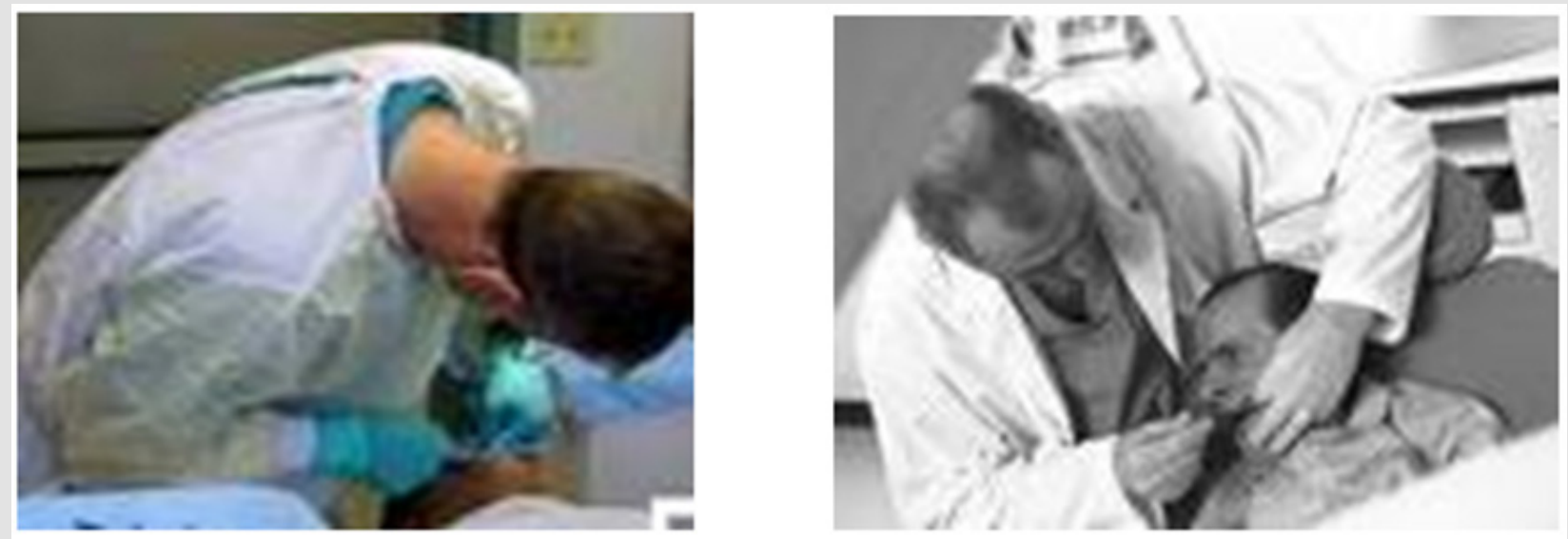

Figure 3. 
Skin

Cutaneous manifestations noted during observation provide useful clues to diagnosis.

Example: Butterfly rash in Systemic Lupus erythematoses (Figure 4).

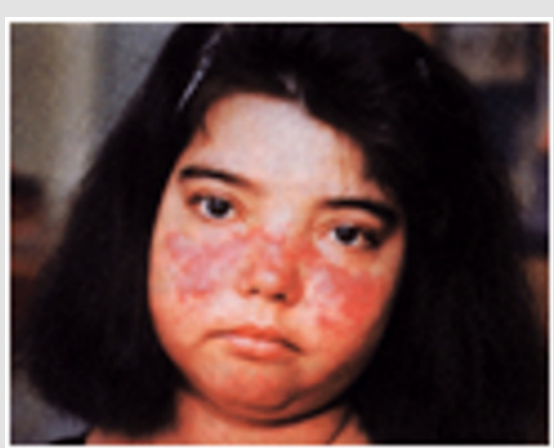

Figure 4.

\section{Hair}

The quantity and quality of hair also contribute a great deal of information in diagnosis SKULL. The skull is examined both by observation and palpation. The multiple abnormalities in the morphology aid in diagnosis (Figure 5).

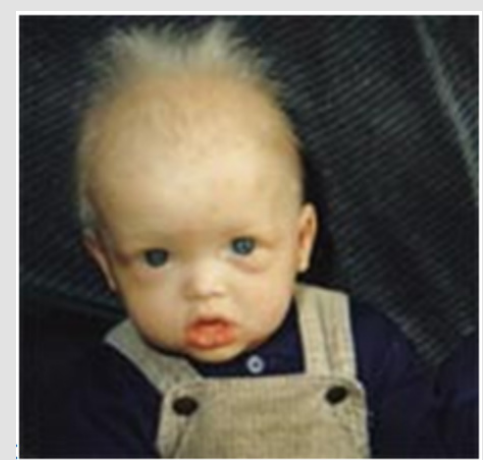

Figure 5.

\section{Skull}

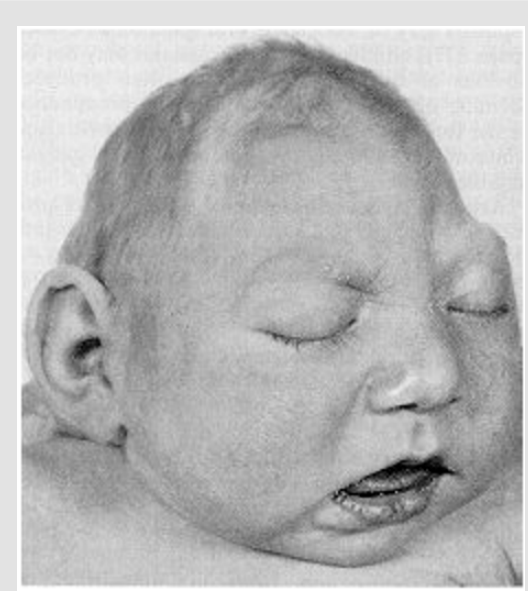

Figure 6: Microcephaly.
The skull is examined both by observation and palpation. The multiple abnormalities in the morphology aid in diagnosis (Figure $6)$.

\section{Hand and Fingernails}

Observation of hands and fingernails is an important aspect of examination. It often reveals signs of underlying disease (Figure 7).

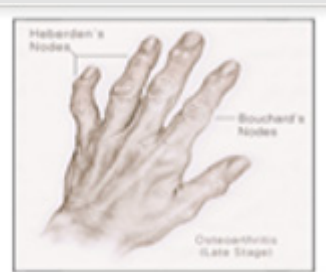

$\wedge$
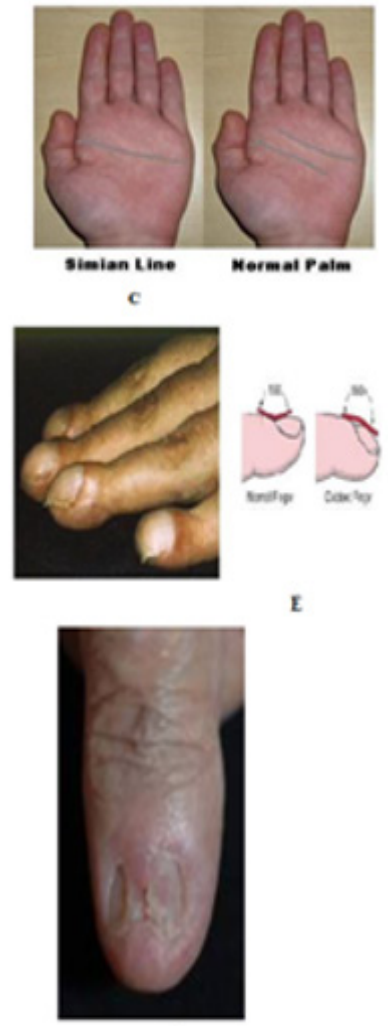

F
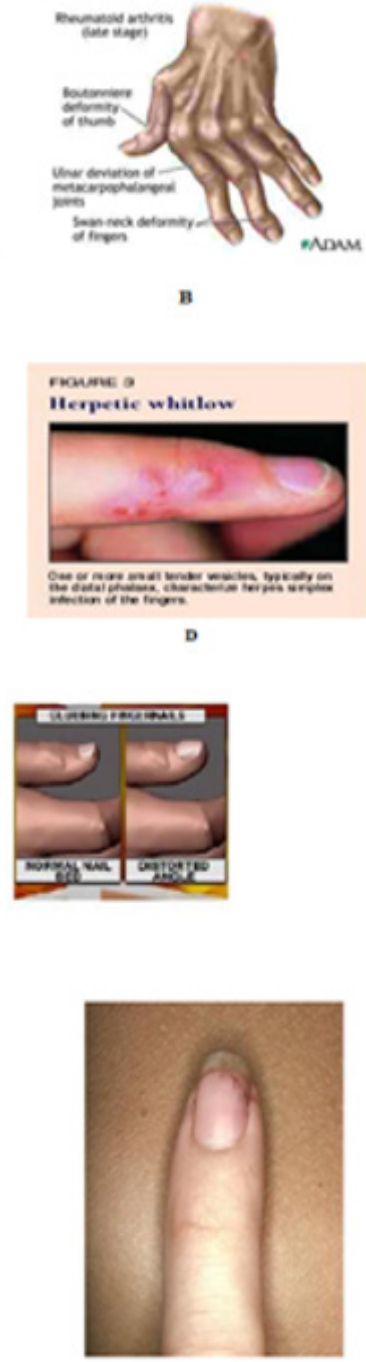

G
Figure 7:

A. Osteoarthritis.

B. Rheumatoid arthritis.

C. Down's syndrome.

D. Herpetic whitlow.

E. Clubbing in Pulmonary and Cardiac Diseases.

F. Pterygium in Lichen Planus.

G. Splinter hemorrhage in Infective endocarditis.

\section{Facial Form}

Recognition of the characteristic facies itself can lead to a diagnosis (Figure 8). 


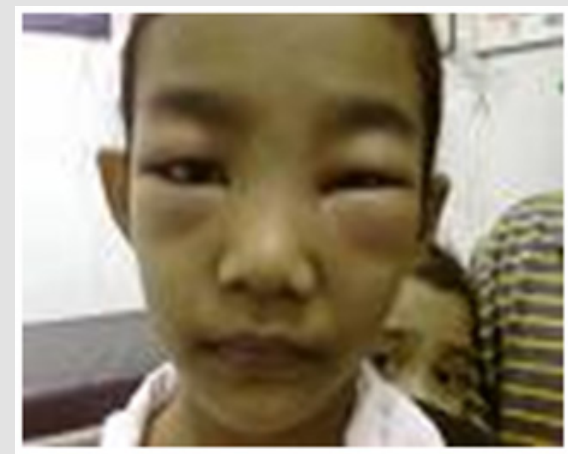

A

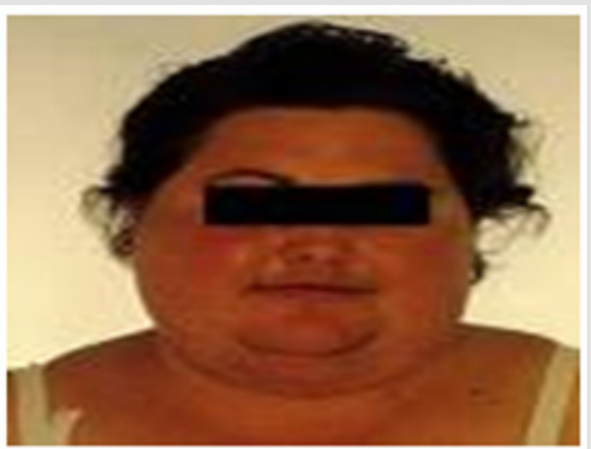

B

Figure 8: A) Nephrotic syndrome Oedematous face with swollen eyes; B) Cushings syndrome Moon Face.

\section{Jaws}

The jaw morphology also provides a clue to diagnosis (Figure 9).

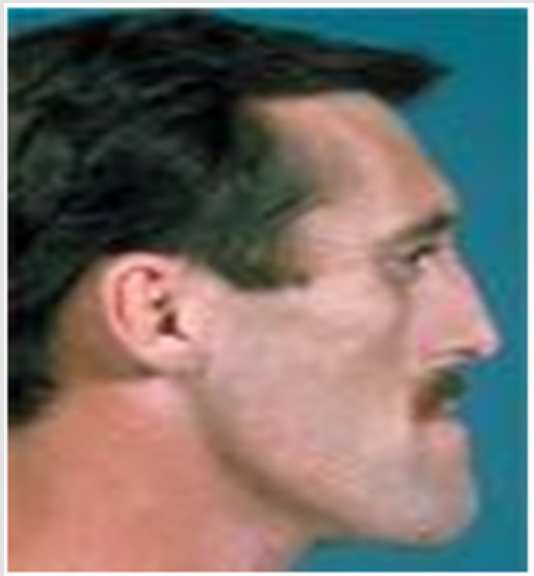

Figure 9: Acromegaly Large and prognathic mandible.

\section{Eyes}

Abnormalities in the eyes can reflect diagnosis (Figure 10).

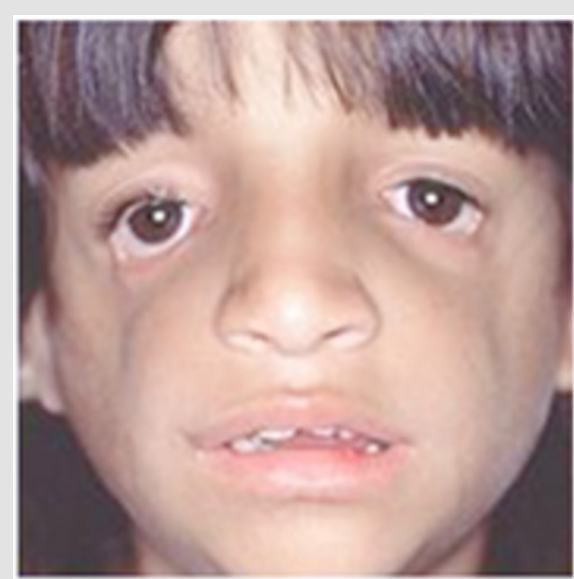

Figure 10: Treacher Collins syndrome Downward sloping eyes.

\section{Ears}

Deformities in ear can contribute to diagnosis (Figure 11).

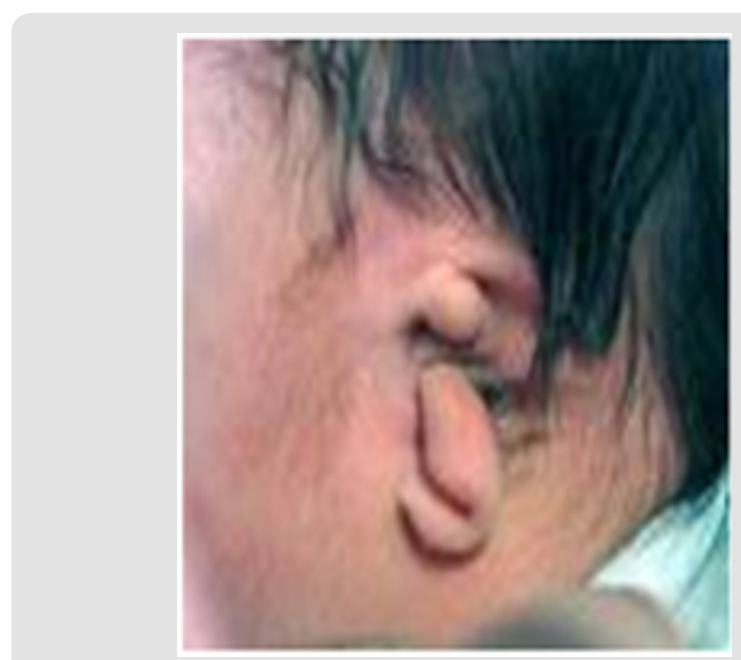

Figure 11: Bixler syndrome Microtia.

\section{Nose}

Morphological alteration in the nose can also lead to a diagnosis (Figure 12).

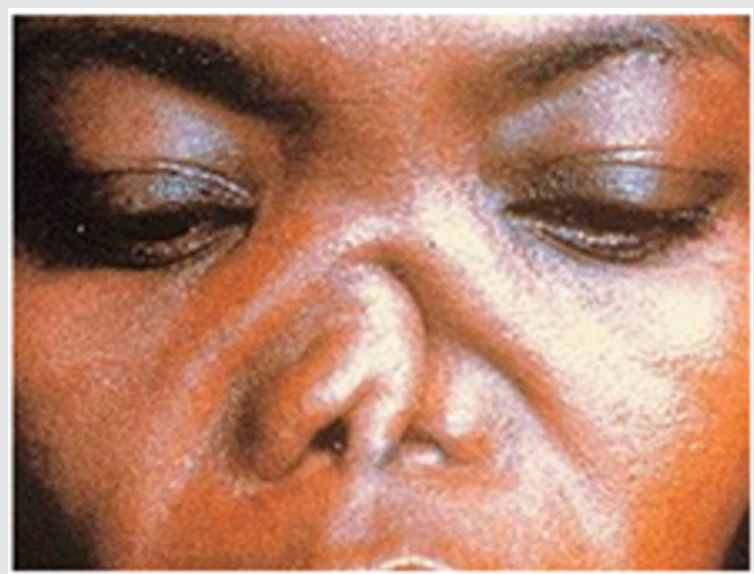

Figure 12: Congenital Syphilis Saddle shaped nose. 


\section{Neck}

Abnormalities in neck can also lead to adiagnosis (Figure 13).

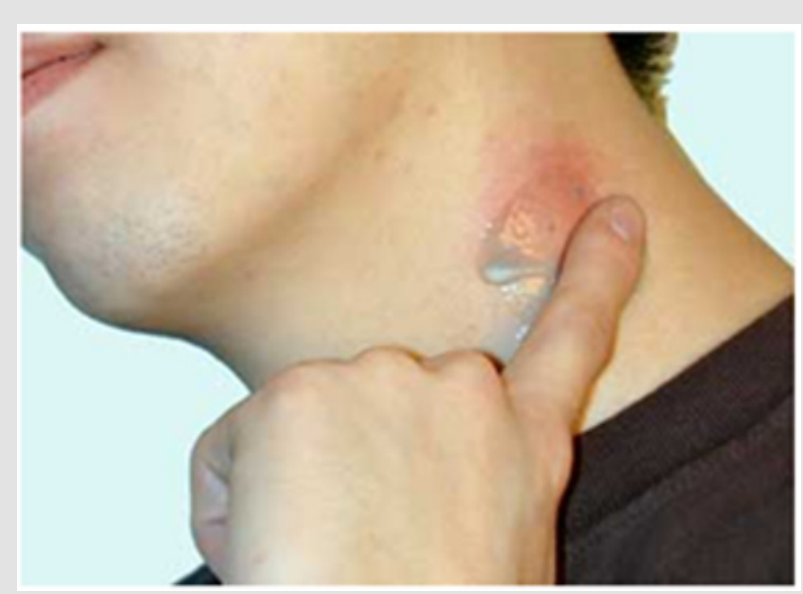

Figure 13: Fiddlers neck in Violin players.

\section{Conclusion}

Holistic dentistry with stepwise general examination contributes a great deal of diagnostic information. To conclude a simple but rationale and judicious approach intermingled with experience can be considered as the hidden precious tool in identifying and managing even the most perplexing diagnostic challenge [1-3].

\section{References}

1. Cinar AB, Murtomaa H, Tseveenjav B (2008) The life-course approach in assessment of dental health: a cross sectional study among Finnish and Turkish pre-adolescents. European journal of dentistry 2: 153-160.

2. Thakur N, Bagewadi A, Keluskar V (2011) Holistic dentistry: Natural approaches to oral health. J Int Oral Health 3: 9-13.

3. Goldstein BH (2000) Unconventional dentistry: Part I. Introduction. Journal of the Canadian Dental Association 66(6): 323-326. 
ISSN: 2574-1241

DOI: 10.26717/BJSTR.2020.28.004709

S Jeelani. Biomed J Sci \& Tech Res

(C) (P) This work is licensed under Creative

Submission Link: https://biomedres.us/submit-manuscript.php

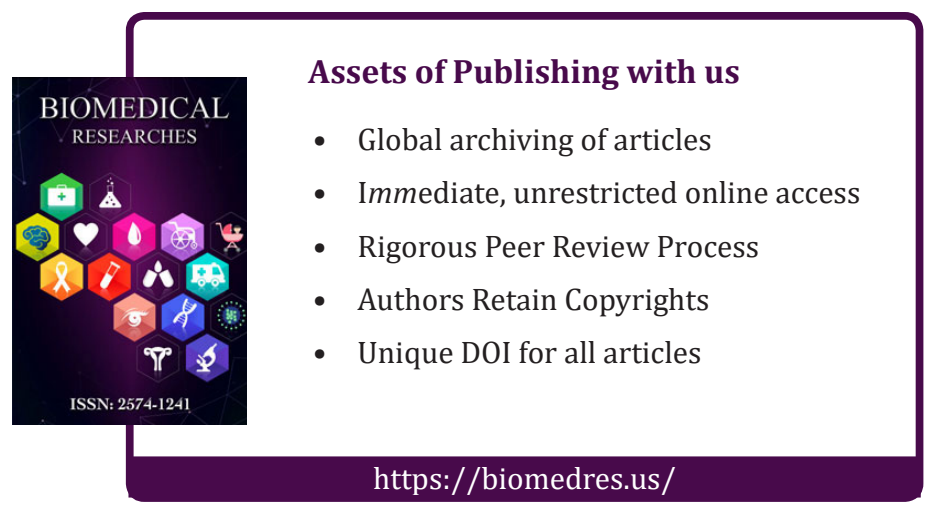

